\title{
Technological stages in the system development life cycle: an application to Web page design
}

\author{
Maria Jakovljevic \\ Department of Information Systems, University of the Witwatersrand, South Africa \\ mariajakov@hotmail.com \\ Piet Ankiewicz and Estelle de Swardt \\ Department of Curriculum Studies, Rand Afrikaans University, South Africa \\ Elna Gross \\ Independent research consultant
}

\section{Contents}

1. Introduction

2. Methodology of instructional programmeme development for Web page design

3. Conceptualizing Web page design through technological stages

4. References

\section{Introduction}

The traditional methodologies of systems design, including Web page design, provide models for the products of software development projects, but fail to concentrate on explicit procedures for setting up and running project development. 'Research has been fairly silent on the question of how best to set up and run multimedia projects from a teacher's point of view' (McGrath, Cumaranatunge, Ji, Chen, Broce and Wright, 1997:21). System design in the information technology environment may not succeed fully unless there is an understanding of the complex thinking processes involved in software development. Complex thinking includes goal-directed, multi-step strategic processes, such as design, decision making and problem solving (Iowa Department of Education, 1989:7; referred to by Jonassen, 1996:27-29). Higher-order thinking includes critical, creative and complex thinking (Jonassen, 1996). For the purpose of this study, complex thinking was used as an umbrella term which included all processes and sub-processes of higher-order thinking.

Methodological aspects of focusing on the problem, performing successful problem analysis and developing critical and creative thinking are not appropriately applied in the Web page design environment. Thus, the needs of system developers are ignored. A problem solving approach as in technology education should be considered by practitioners (e.g. project designers, programmers and educators) in the learning area information technology.

This article reports on a theoretical investigation into the manner in which different mind tools (databases, semantic networks, computer-mediated communication, multimedia and programming) and instructional strategies influence Web page development during the various technological stages. Mind tools 'support, guide and extend the thinking processes of their users' (Jonassen, 1996:10).

The investigation relies on both behaviourist and constructivist theoretical approaches and the 
critical importance of learning outcomes (problem solving, decision making, using critical and creative thinking) that are emphasized by many educators (e.g. Mebl, 1997: 31-37) and the South African Qualification Authority (South Africa, 1997:92).

The rest of the article is organized into the following sections:

Methodology on instructional programme development (the framework and background on complex thinking, mind tools, learning theories and instructional strategies; specification of the instructional programme)

Conceptualizing Web page design through the technological stages (discussion of the basic tenets of the influence on the information technology (IT) learning environment).

This article is organized within a structure that provides a conceptual framework and contains different key elements highlighting their logical flow (see Figure 1). Each element of the Figure is discussed in the subsequent sections. This includes identifying needs, stating the problem leading to a detailed examination of main issues such as complex thinking, mind tools, and policy documents. These will bring us to criteria and finally to the instructional programme and technological stages.

Figure 1 Overview of the article and the methodology of the programme development

\section{AN OVERVIEW OF THE PAPER AND THE METHODOLOGY OF THE PROGRAM DEVELOPMENT}

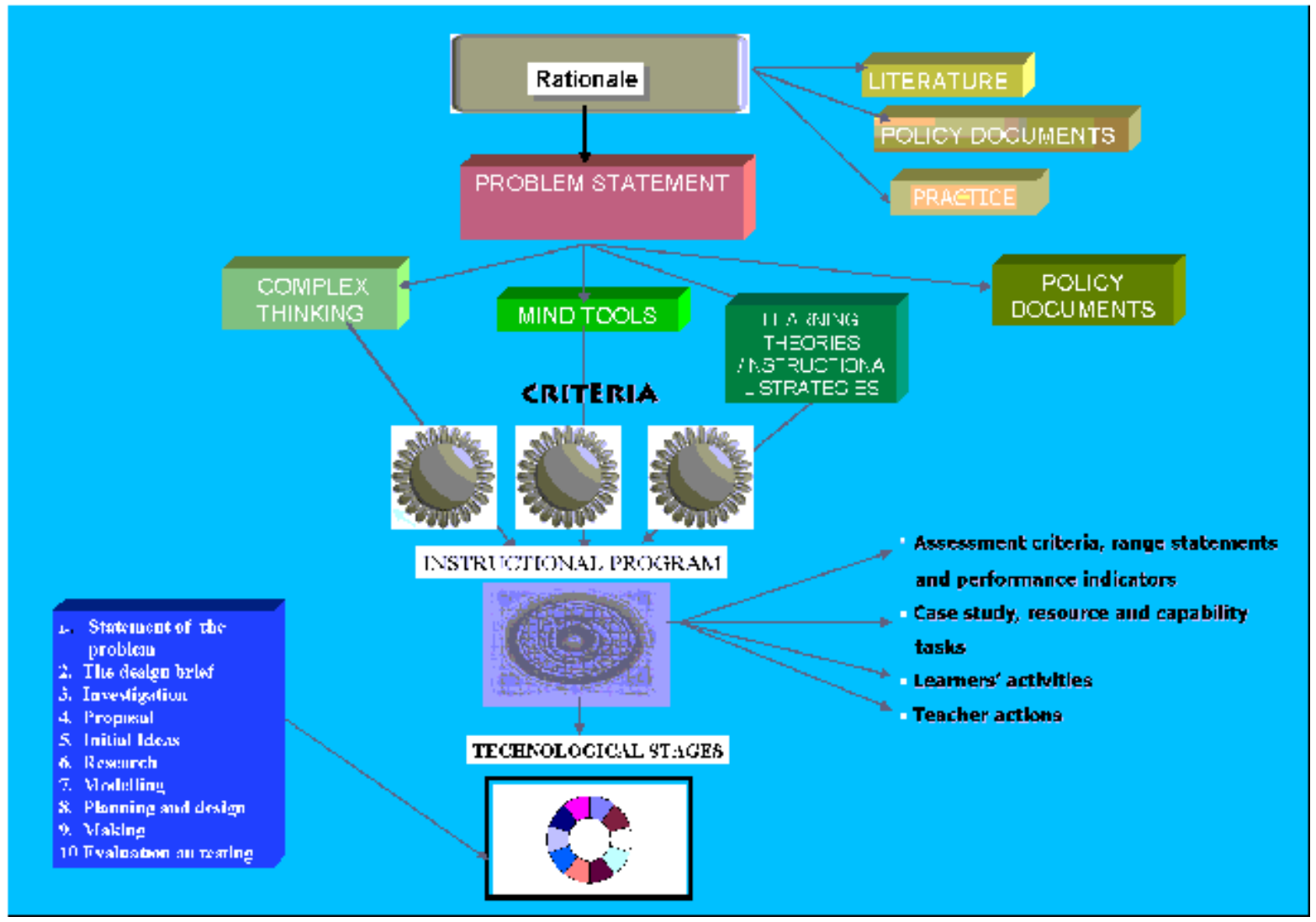

The following sections describe the methodology of instructional programme development and the implications of the technological stages for information system design. In the next section, the rationale, necessity of complex thinking, mind tools and instructional strategies will be discussed. 


\subsection{Rationale}

Very little has so far been evident in the literature on the construction of a learning environment that will engage students in the development of cognitive skills and create a multimedia Web page, using present instructional resources. Learners are not given real-world problems, nor are assignments given according to their previous experience.

The development of a multimedia product by learners is a desirable, and an often overlooked, fact. In the current climate, Web design consists of developing multimedia, bringing together all the technological capabilities of multimedia with the interactive capabilities of networks (Morris and Hinrichs, 1996:1-7). Web design utilizes multimedia design technology (Ridley and Ridley, 1996:34). According to Jonassen (1996:185), 'there is little current research on learning effects from multimedia'. Similarly, McGrath et al. (1997:21) states: 'There is very little research on constructivist (student-constructed) multimedia and hypermedia'. However, programmeming tasks are rewarding if students are encouraged to construct models made up of sound, text and graphics. Thus, students' educational experience is enriched by developing multimedia materials.

The experience of the researcher and other educators on higher educational level reveals that during system analysis learners express the need for efficient representational means to comprehend the link between system analysis diagrams, for example the entity relationship diagram, and the data flow diagram. According to Davies (1996; referred to by Welch, 1998:244) visualizing of 'the whole or component parts of the product and its finished appearance' is important in project development.

In the information technology learning area, students are expected to critically evaluate information, to design and very often to create a new product. Multimedia are, without a doubt, a key topic for the current and future application of information technology. However, the present teaching practice does not raise students' awareness of the importance of reflecting on, and exploring, a variety of strategies so as to learn more effectively.

From the above introduction it appears that the development of complex thinking using mind-tools, aided by appropriate instructional (teaching/training) strategies, is an issue of fundamental importance.

Taking into account previous research findings and conclusions set out above, the following research question is put forward:

What are the implications of technological stages, complex thinking, mind tools, learning theories and instructional strategies for an instructional programme in information system design?

It is important to investigate the characteristics and the relation between complex thinking, mind tools, learning theories and instructional strategies and their influence on criteria that would form a framework for such an instructional programme. These aspects represent key factors generally focused around the technological process. Thus, the argument is that the following dimensions are important and necessary variables that must be incorporated into the conceptual framework for technological problem solving and information system design: complex thinking, mind tools, instructional strategies, policy documents and practice.

\subsection{The design process, thinking skills and instructional programme}

In this section some ideas and models of complex thinking are discussed and the possible implications for instructional methods concerning information system design are indicated. By understanding the thinking processes, we could nurture ideas that we generate about multimedia Web page construction. Knowing the process the mind goes through, will be the basis for arranging activities and strategies in order to undertake project development. There is a need for the clear specification of the skills that students need for design tasks, and prescriptions how teachers can effectively support these skills (Carver, Lehrer, Connell and Erickson, 1992:386-387).

Ankiewicz, De Swardt and Stark (2000:122) propose a model of different thinking sub-processes 
that constitute the technological process. These authors state that the technological process integrates the following clearly identifiable sub-processes:

- Thinking process (creative and critical)

- Decision-making process

- Problem solving process

- Design process

These authors argue that if these processes with their associated steps interact with each other they act as sub-processes of the technological process (see Figure 2). According to Ankiewicz et al. (2000:122) 'critical and creative thinking is required for decision-making; decision-making is necessary in order to solve a problem and problem solving is a prerequisite for design'.

Figure 2 Model of the processes that constitute the technological process (Ankiewicz et al., 2000)

\section{A MODEL OF PROCESSES THAT CONSTITUTE THE TECHNOLOGICAL PROCESS}
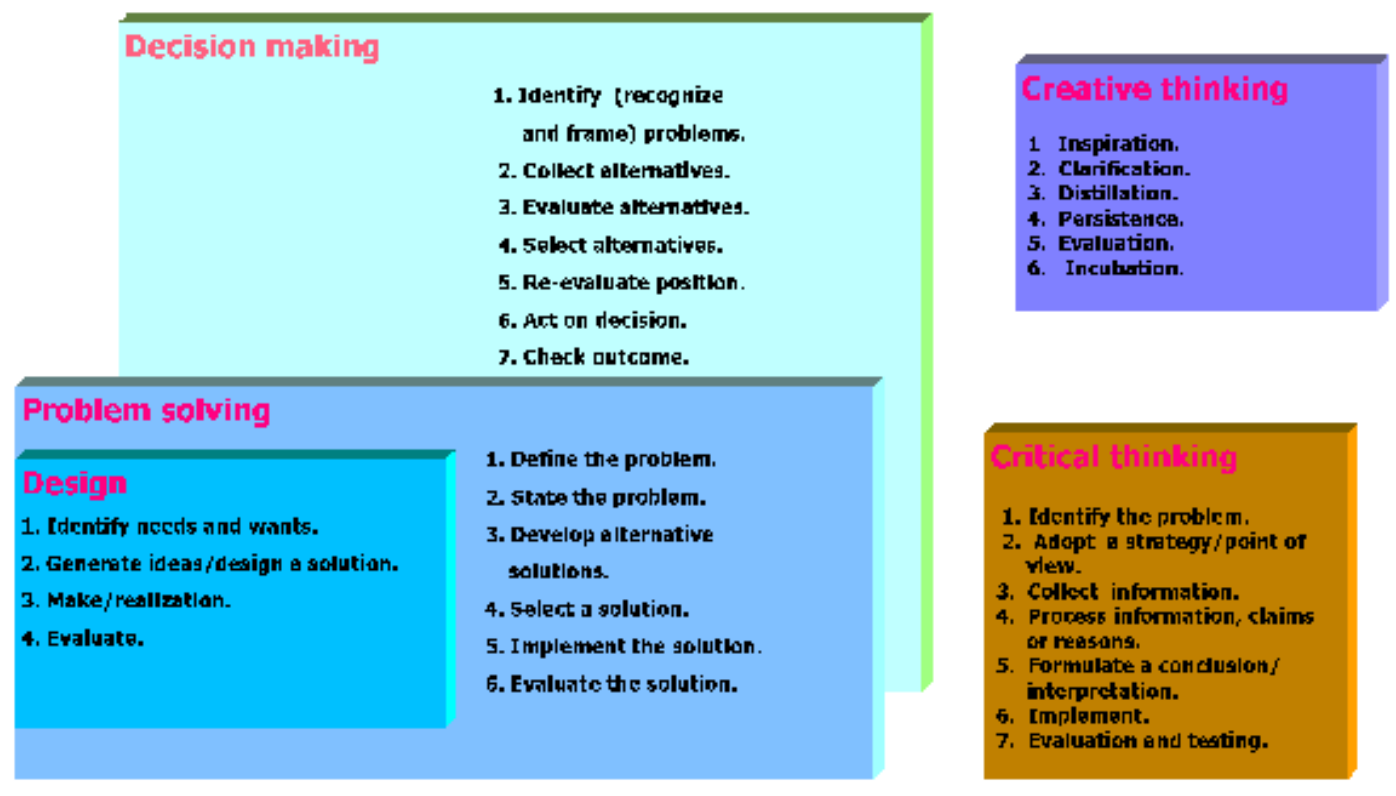

In addition to this model, Marzano, Brandt, Hughes, Jones, Presseisen, Rankin and Suthor (1988; referred to by Johnson, 1997:162-163) developed a model of thinking (Figure 3) particularly useful for technological practice. According to them the primary dimensions or key aspects of intellectual skills are thinking processes, thinking skills, critical and creative thinking as unique types of thinking processes, and metacognition.

Figure 3 Model of thinking (Marzano, et al., 1988; referred to by Johnson, 1997:162-163) 
KEY ASPECTS OF INTELLECTUAL SKILLS

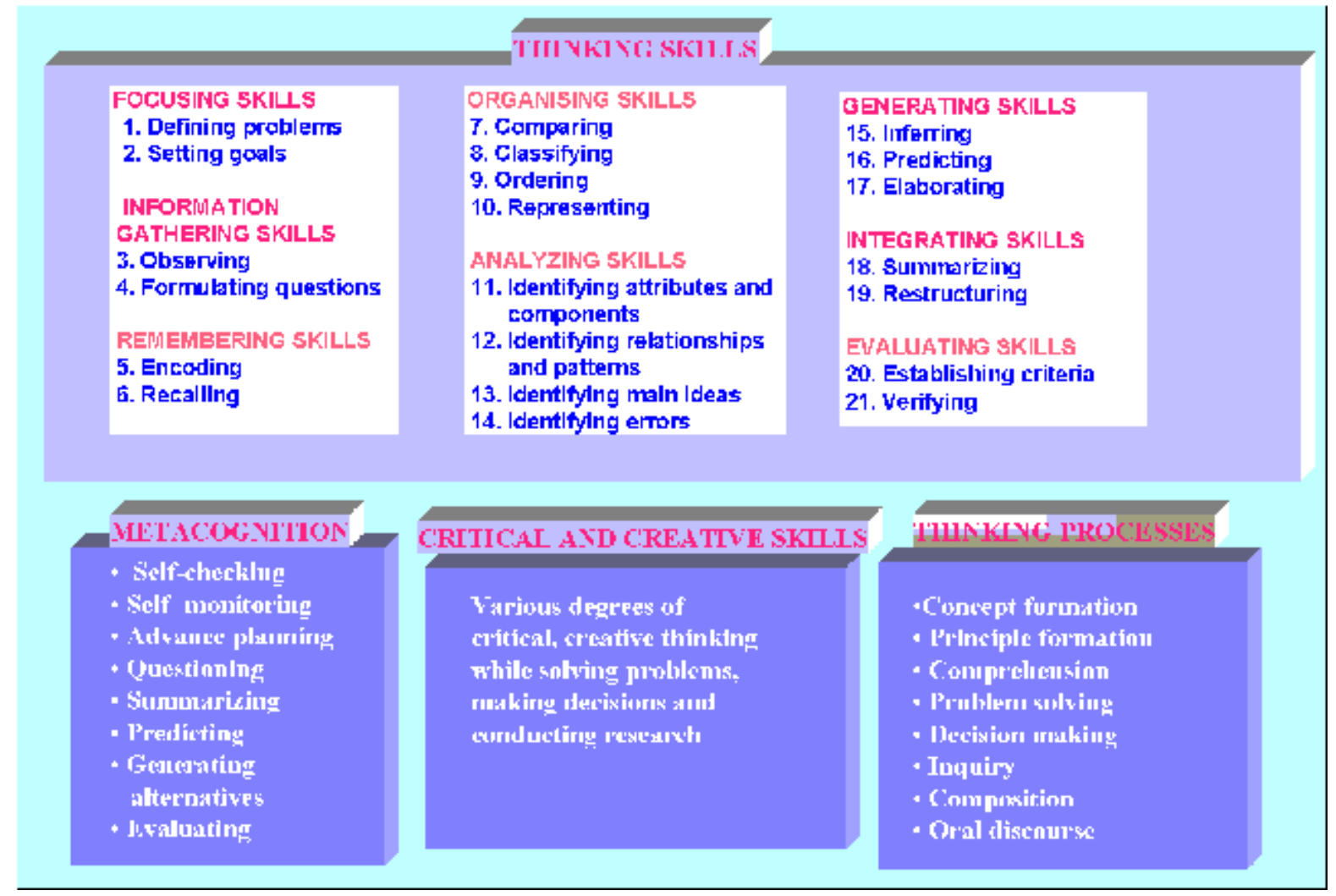

Carver et al. (1992:388) created a model of design skills (see Figure 4) that is important for project development within the hypermedia environment, including:

- Project management skills

- Organization and representation skills

- Presentation skills

- Research skills

- Reflective skills.

Figure 4 Model of design skills (Carver et al., 1992:389) 


\section{DESIGN SKILLS}

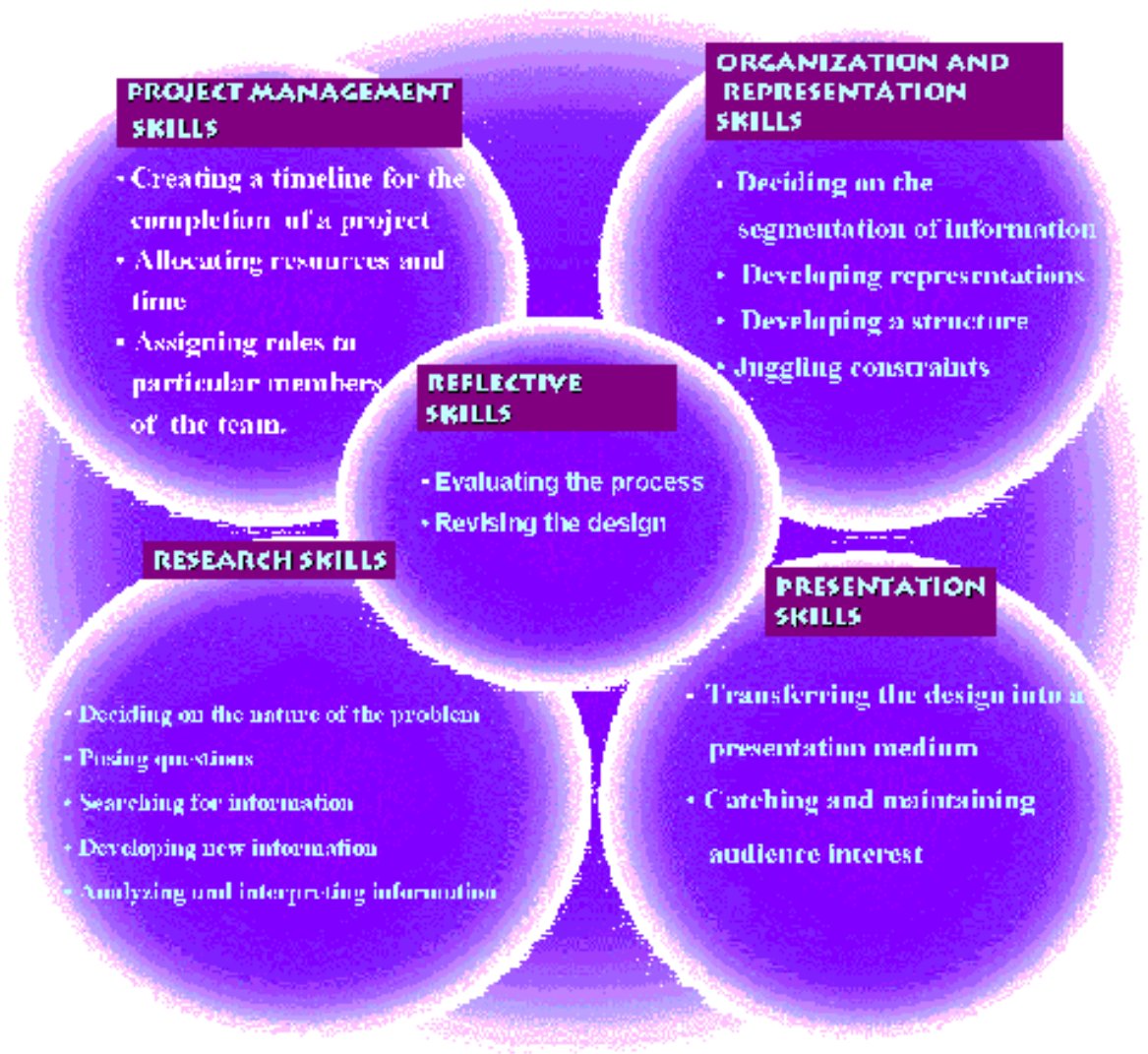

Carver et al. (1992: 389) point out that the reflective skills (evaluating the process; revising the design and the final product) are essential parts of a design process. The reflective skills of predicting, planning, checking, monitoring, reality testing, coordinating, controlling (Schepens, Streumer and Tricht, 1981, referred to by Doornekamp and Streumer, 1996:63) help learners to work independently on a task. But, the novice problem solver has no metacognitive (reflective) skills (Doornekamp and Streumer, 1996:63). The fact that reflective skills are necessary for technological design implies that learners should explicitly be taught reflective skills, thinking skills in general (Beyer, 1991:33) and other technological processes and skills (Ankiewicz et al., 2000:122).

Beyer (1991:32) specifies that defining thinking skills and their attributes (a procedure, the rule or principle, criteria or other knowledge) and communicating these to the learner enhance task execution and thinking in general. In addition, Bellanca and Fogarty (1991, referred to by Fogarty and McTighe, 1993:163) highlight the idea that learners should facilitate thinking 'with the appropriate processing tools, cooperative learning and graphical representations of their thinking'.

The above-mentioned models contain a variety of skills necessary for project development. These models and conceptions of the design process and thinking in general coupled with the ideas and strategies of Beyer (1991:33) and Bellanca and Fogarty (1991, referred to by Fogarty and McTighe, 1993) form the framework for this study that could lead to an opportunity to develop an instructional programme applicable to Web page design.

Thus, the design process requires the skill of visualizing, cooperative learning and representational means. Graphical representational tools, mind tools and cooperative learning were key issues in this study. These issues are now discussed. 


\subsection{Implications of using mind tools in a collaborative multimedia Web page environment}

Dawkins (1986, referred to by Starfield, Smith and Bleloch, 1990:ix) states that computers do not only stretch the imagination; they also discipline and control it. Researchers agree that mind tools are cognitive tools that are 'intended to facilitate cognitive processing by engaging the learner in critical thinking' (Komers, Jonassen and Mayes, 1992; Jonassen, 1993). With powerful but easily learned software such as spreadsheets (Starfield et al., 1990: ix) and the whole range of mind tools (Jonassen, 1996) we could bring the development of systems within everybody's reach.

For students to be active in building their own deep understanding of ideas and the relationships between ideas while designing information systems, the researcher has adopted the following powerful aspects of mind tools, aiming at improving thinking processes:

- Current research on multimedia instruction and mind tools (Jonassen, 1993; Lehrer, Erickson and Connell, 1996; Jonassen, 1996) support the idea of using the tools in all learning areas to encourage students to think and develop complex thinking. However, mind tools should be used collaboratively. As Jonassen (1996:2) says, 'mind-tools are best used collaboratively, and they provide an opportunity for students to share ideas'. Group work around the computer enables learners to go further in developing their powers of problem solving.

- It is generally accepted that computer programmeming facilitates the development of abstract thinking, problem solving and logical thinking (Dover, 1983, referred to by Schnider, 1987:47). Programming tasks leave students with a great variety of misconceptions and shortfalls in problem solving. Using computer programming as a mind tool that promotes learning/thinking can be more effective in collaborative group work (Harel and Papert, 1990:3). Research and observations on real programmeming reveal the intensely difficult tasks for individuals at the introductory level and in the cooperative nature of the work.

- Jonassen (1996:193-197) believes that 'learners should use the media to generate their own instruction, and they should also create a multimedia product acquiring cognitive, metacognitive and motivational advantages. When learners become designers, they engage readily and willingly in higher-order thinking.' Carver et al. (1992) mention the importance of hypermedia design and analysed cognitive skills involved in designing hypermedia projects.

- Collaborative database projects will probably be more productive than individual projects (Jonassen, 1996:64). Group learning techniques in group projects, where students carry out project work in small groups, promote the constructive exchange of ideas. In the list of critical learning outcomes, the learning outcome to 'work effectively with others as members of a team, group, organisation and community' (South Africa, 1997:13) will probably not be realized if collaborative work is not encouraged and properly organized. Jonassen (1996:207) points out that 'because of the complexity of the process and the amount of research and background work required (e.g. finding visual and auditory material to include in the presentation) multimedia construction is probably the mind-tool that most requires collaboration'.

- Von Wodtke (1993:96) states that semantic network diagrams by their visual power help to express concepts and relationships between them. Semantic networks can be used for the conceptual representation of ideas in planning the multimedia Web page design process. Jonassen (1996:96) says that semantic networks can be used as a planning tool and also as 'conceptual models for structuring hypertext and hypermedia systems' (Jonassen, 1991). The learners are involved in segmenting, linking information into nodes, deciding on and describing the representation of ideas.

- Computer-mediated communication (CMC) assesses and supports information retrieval, email facilities, knowledge acquisition through internal negotiation and integration of meaning making. 'CMC acts as a vehicle for delivery and sharing the products of any other mind tool' (Jonassen, 1996:170).

Therefore, mind tools (e.g. multimedia and hypermedia construction, programmeming, databases, semantic networks, computer-mediated communication) can be adapted to extend cognitive functioning during learning so as to engage learners in a cognitive operation while acquiring knowledge (Pea, 1985; referred to by Jonassen, 1996). 
Practical and theoretical perspectives provide an indication of a need for training in the programming classrooms in the Information Technology learning area. This confirms the notion that the present instructional materials and strategies tend to have some negative effects on the learning outcomes. Therefore, it is imperative to analyse the state of instructional methods from practical and theoretical perspectives in order to be able to design and implement an instructional programme to readdress the instructional aspects concerning student-designed multimedia Web page projects. This brings us to the last issue that should be investigated, namely learning theories and instructional strategies.

\subsection{Learning theories and instructional strategies in the context of this study}

There is a need for explicit instructions and specific strategies for Web design processes. Eggan and Kauchak (1996:52) agree that teachers should make students aware of the learning process. Perkins, Goodrich, Tishman and Owen (1994:5-34) suggest the idea of 'knowledge as a design', which applies the use of discussion in the classroom that involves purpose, structure, model classes, evaluative arguments, pros and cons, explanatory argument and closure. According to Gardner and Hatch (1983), learners with different dominant intelligence (e.g. artistic, linguistic, logicalmathematical, spatial, the personal, bodily kinesthetic and musical) can practise their skills through design activities.

There are no adequate learning theories on which to base the design of hypermedia systems (Jonassen, 1996). McMurdo (1998:195) provides some guidelines for writing good hypertext and producing successful Web pages. As intellectual skills are the focus of technological design, a better understanding of socio-constructivist theories of learning is needed (Johnson, 1997:177).

Constructivists claim that learners construct their knowledge according to their own beliefs, experiences and previous knowledge structures. Through mind tools and constructive learning involved in project design, students will foster integrative, reflective and goal-orientated thinking (Jonassen 1991, 1996; Norman, 1993; referred to by Jonassen, 1996:12; Simmons, 1993). Constructivist classrooms promote sustained collaborative projects and the creation of authentic assignments (McGrath et al., 1997:19).

Contrasted with constructivism is behaviourism which emphasizes the use of behavioural objectives, skill practise and assessment of skills and sub-skills (Wheatley, 1991:19). Information system design is an area of skill and knowledge. Direct instruction is necessary to suit learners' needs when using mind tools in preparation for creativity and innovation. Thus, the behavioural approach is applicable to technology learning if students need to develop a skill in using operating tools or to memorize important information (Johnson, 1997:177).

Within the framework of these theoretical perspectives, four conceptions of instruction influence the rationale for the use of mind tools in this research: constructivism, Perkins's $(1986,1994)$ concept of 'knowledge as design', Jonassen's (1996) ideas, and Gardner's theory of multiple intelligences (Gardner and Hatch, 1983:4). Acceptance of multiple perspectives is an important attribute in the learning process.

Table 1 depicts approaches/strategies of instruction and their application in this study.

Table 1 Learning theories, instructional approaches and strategies in the context of this study

\begin{tabular}{||l||l|l|l||}
\hline $\begin{array}{l}\text { Instructional } \\
\text { approaches }\end{array}$ & $\begin{array}{l}\text { Sub- } \\
\text { approaches }\end{array}$ & Instructional strategies & $\begin{array}{l}\text { Instructional strategies used } \\
\text { in this study }\end{array}$ \\
\hline \hline Behavioural & & Lecture-discussion & Lecture \\
\cline { 2 - 4 } & & Demonstration & $\begin{array}{l}\text { Demonstration } \\
\text { Direct instruction }\end{array}$ \\
\hline \hline Constructivism & $\begin{array}{l}\text { Co-operative } \\
\text { Discovery } \\
\text { Inquiry } \\
\text { Experiential }\end{array}$ & $\begin{array}{l}\text { Discussion } \\
\text { Brainstorming } \\
\text { Group work } \\
\text { Debate }\end{array}$ & $\begin{array}{l}\text { Discussion } \\
\text { Brainstorming } \\
\text { Group work } \\
\text { Debate }\end{array}$ \\
\hline
\end{tabular}




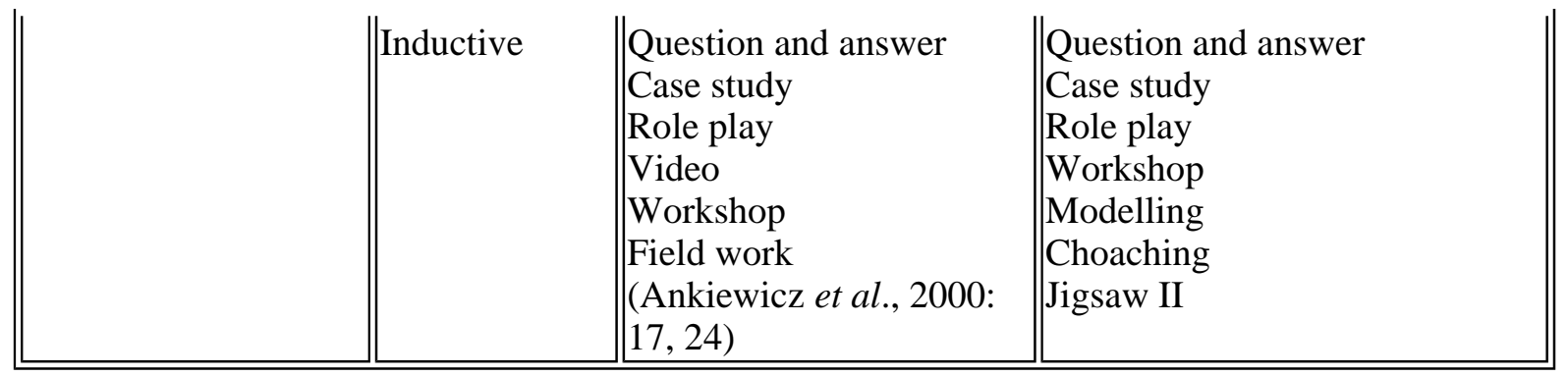

The discussion now turns to a closer examination of the nature of some instructional approaches that offer possibilities for use in information system design.

Direct instruction is characterized by teacher explanation and modelling combined with student practice and feedback to teach factual knowledge and basic skills (Eggen and Kauchak 1996:186).

The collaborative nature of the design process and the public nature of its products motivate students because of the ownership of a topic (Collins, Hawkins and Carver, 1991; referred to by Carver et al., 1992:386). Jigsaw II is a form of collaborative learning in which individual students become experts on subsections of a topic and teach that subsection to others. Vockell and Deusen (1989:24-28) state that peer tutoring and peer modelling are extremely effective for promoting higher-order thinking. But in a specific context domain including the IT learning environment, 'guidance must be given about how to evaluate; learning in technology does not happen by discovery' (Jones 1997:93).

Research support experiential learning (Little, 1993; Laurillard, 1994). Experiential learning is 'a perspective on learning that combines experience, perception, cognition, and behavior' (Kolb, 1984:4, referred to by Little, 1993:443-444). Problem solving is enhanced through pupils attempting the 'real world' technological problems, because design and technology relies heavily on experience (Shield, 1996).

The major aim of inquiry teaching is to simulate independent thinking (Smallwood, 1995:5). The inquiry model developed by Suchman is based on the premise that the intellectual strategies used by scientists to solve problems and inquire into the unknown can be taught to learners (Gunter, Estes and Schwab, 1995:159).

Creative teachers combine and adapt instructional models applying mini lessons depending on a specific goal of teaching (Eggen and Kauchak,1996:327). In the next section some aspects from policy documents relevant to information system design are explained. Components of the instructional programme will then be analysed and attention will be drawn to technological process and stages that form a basis for an innovative approach to software design.

\subsection{Framework for instructional programme}

Given the definition of key factors related to technological problem solving and information system design, there is a serious need for establishing criteria based on perspectives of complex thinking, mind tools, learning theories and instructional strategies. It is clear that these key factors have forceful qualities that served as a source from which the relevant criteria are drawn, which are at the heart of this study.

It is essential that these sources are applied to technological design because they will help learners to reflect critically and creatively on information systems design issues. Criteria cover a broad spectrum of ideas and conclusions that can be defined in terms of teachers actions, tasks, activities, tools, techniques and thinking skills, which constitutes a basis for a structured instructional system. Given this important point, the remainder of this section focuses on analysing the structure of the instructional programme.

The instructional programme is based on the policy documents regarding technology education (Department of Education, 1997; South Africa, 1997; Technology 2005, 1996). Criteria and policy documents form a fundamental basis for the instructional programme. 
The following components of the programme are included with reference to specific outcomes, critical outcomes (see Figure 5), assessment criteria, range statements and performance indicators proposed by policy documents:

- Case study tasks (help learners to connect classroom activities with community)

- Resource tasks (help learners to develop knowledge and understanding of a particular problem, including skills in using mind tools, programming languages, semantic network tools, databases)

- Capability tasks (help learners to perform detailed actions that are spread across the technological process. These tasks are based on case study tasks and resource tasks that will empower learners with technological skills and knowledge)

- Assessment criteria (AC)

- Range statements (RS)

- Performance indicators (PI)

- Critical outcomes

- Specific outcomes

- Notional time

- Technological stages (see Figure 6)

- Instructional strategies

- Teacher/tutor actions

- Off-line activities

- On-line activities (browsing, searching, learning, organizing and synthesizing information)

- Team structure software process (TSSP) methodology (Greenberg and Lakeland, 1999:2) for Web page design.

Figure 5 Critical and specific outcomes in technology education

\section{CRITICAL OUTCOMES (CO) AND SPECIFIC OUTCOMES (SO)}

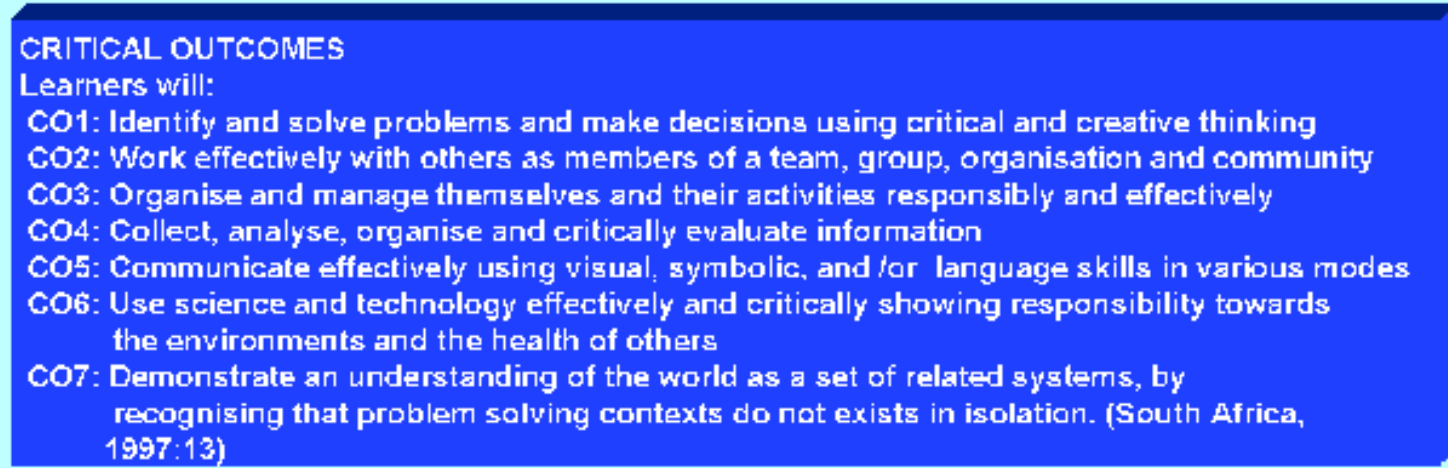

\section{SPECIFIC OUTCOMES}

Leamers should be able to:

SO1: Understand and apply the technological process to solve problems to satisfy needs and wants

SO2: Apply a range of technological knowledge and skills

SO3: Access, process and use data for technolog ical purposes

SO4: Select and evaluate products and systems

SO5: Demonstrate and understanding of how different societies create and adapt technological solution to particular problems

SO6: Demonstrate and understanding of the impact of technolagy

SO7: Demonstrate and understanding of how technology might reflect difierent biases and create responsible and ethical strategies to address them. [DOE, 1997:7-25]

The components, and a range of mind tools, worksheets and guidelines shape an instructional 
programme that could help to define some direct and indirect indicators of complex thinking through Web page design.

There is a wide range of research findings related to problem relevance, criteria and tasks settings. Learners are now being encouraged to look for their own problems and investigate the context of their design tasks (National Curriculum Non-statutory Guidance, 1990; referred to by Johnsey, 1995:208-209). Furthermore, learners should be involved in identifying needs and opportunities through the investigation of context, 'while teachers are more involved in setting the task' (Technology in the National Curriculum Non-statutory Guidance, 1990; referred to by Johnsey, 1995:204). Learners are to be encouraged to develop criteria against which products can be evaluated before developing their design proposal.

In the next section the major components of the instructional programme and their relationship in framing the technological process are discussed.

\subsection{Instructional programme}

Assessment criteria (AC), performance indicators (PI) and range statements (RS) accompany the instructional programme. These sources lead to the creation of case study tasks, capability tasks and resource tasks that are adapted to the particular problem in this research. Allocated tasks influence the derivation of off-line and on-line activities. The activities are accompanied by appropriate actions by the teacher to set up a design environment through collaborative groups that could yield new software design inventions. Tasks and activities were selected and created according to TSSP methodology and are based on criteria drawn from theoretical perspectives on mind tools, complex thinking, learning theories and current instructional theories. Criteria are based on constructivist and behaviourist learning theories. Different technological assessment procedures based on performance indicators (PI), peer evaluation and product evaluations are introduced.

An innovative structure of the instructional programme leads to the need for technological stages (see Figure 6) in order to promote complex thinking and one or more specific technological outcomes through the creative use of instructional strategies and Web page design principles.

'The most successful technology education programmes strive to promote pupils "ownership" of problems' (Hennessy and McCormick, 1998:106). A team approach should yield a larger opportunity for exchange of information and easing the individual load in information system design.

As the instructional programme has the systematic structure of the technological stages, combined with an emphasis on information system design and mind tools, the practicability of such a combination is one of the aspects of the further analysis. The results of the analysis of the instructional programme will influence development of an instructional model that could help us to promote complex thinking through Web page design.

\section{Conceptualizing Web page design through technological stages}

The innovation of this research is to combine information system design methodology with the framework for technology education. Implications of this perception of the information systemstechnology education interface are important because of the similarity of perspectives they bring to the study of design, problem solving and invention. By regarding information system design as a technological process we can use the technological stages (see Figure 6) as a framework for building a software product. The technological process is divided into stages, where each stage indicates a period of time where a discernable activity takes place (Ankiewicz et al., 2000:122). The stages of the technological process with its sub-processes (see Figure 2) aims to provide chronological guidelines to follow during technological design. According to these authors each stage of the technological process can consist of more than one sub-process. The technological process is a cyclic process and its elements can be rearranged, substituted and even deleted. 
Furthermore, throughout the technological stages, we refine the problem solving process. In the normal school curriculum the technological process is a strand that is divided into the following substrands: investigate, design and plan, make and evaluate. The sub-strands rather correlate with the steps of the design process. The technological stages extend the current sub-strands and provide guidelines for system design.

Technological stages refine the process of technological problem solving, because they are based on criteria drawn from theoretical perspectives on mind tools, complex thinking, learning theories and current instructional strategies. The diagram depicted in Figure 6 provides the illustration of the technological stages with a brief description.

Figure 6 Technological process (adapted from Ankiewicz et al., 2000)

\section{TECHNOLOGICAL STAGES}

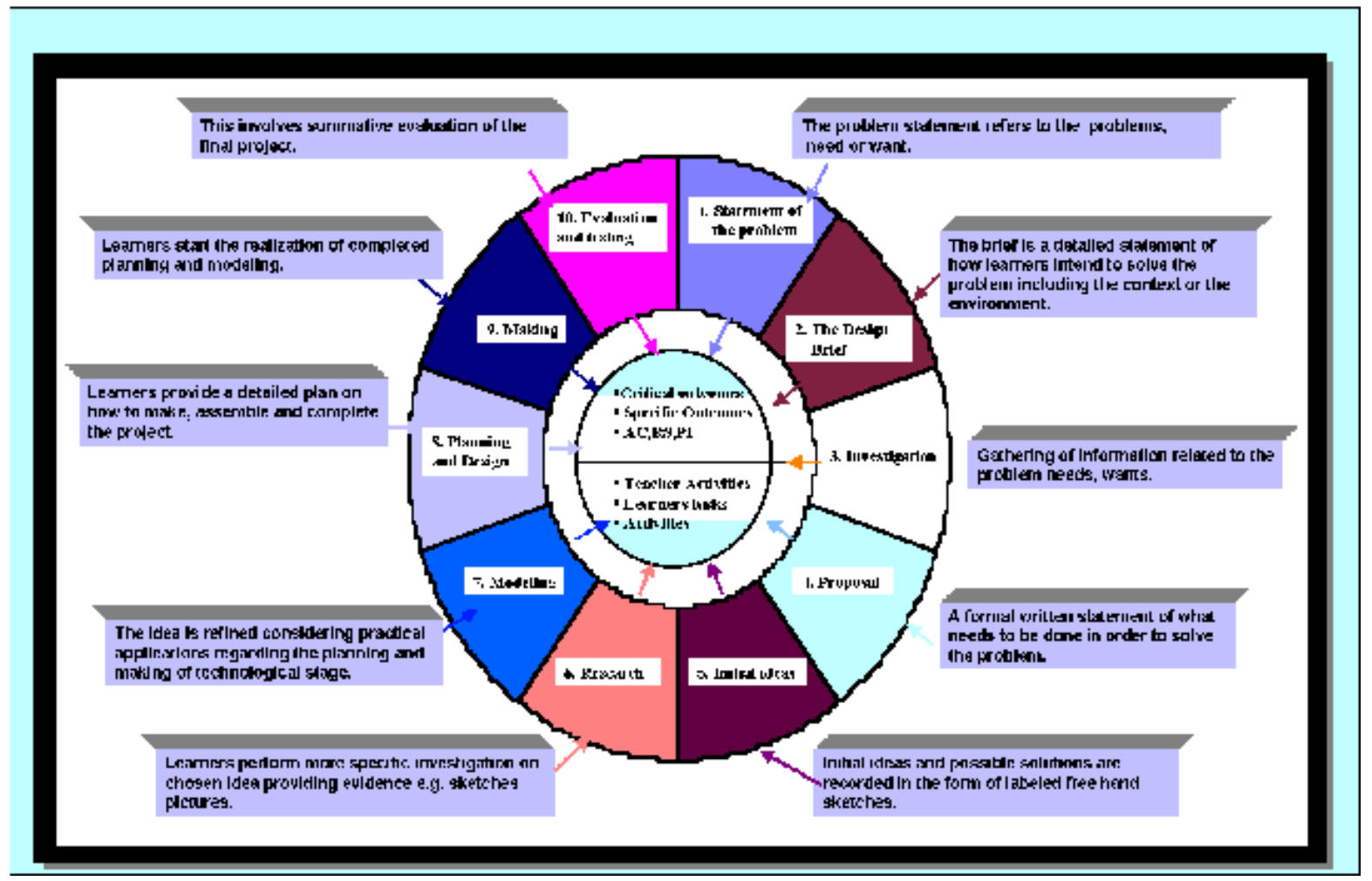

During the technological stages the concept of an information system is gradually built up. We introduce the concept of a system that takes data inputs from sources through collection processes to stored data, and through extraction processes retrieve data yielding a desired output for a particular user.

When designing a Web page as an information system, we take into account the function triangle proposed by De Vries (1999:23). Learners will develop an understanding of the relationship between

- the function that it is to be fulfilled;

- the data, which have to be included in the Web page, the meaning and appearance of the data; and

- treatments that are necessary to shape a Web page.

Thus, the advantage of the functionally and strategically similar processes used in technological problem solving and information systems will be applied in this research.

Technological stages (see Figure 6) were used as a frame through which the Team Structure Software Process (TSSP) methodology was implemented (see Figure 7). TSSP methodology is borrowed from the Software Services Outsourcing Programme (SSOP) of the HP Consulting 
(Greenberg and Lakeland, 1999:2-3).

Figure 7 TSSP methodology

\section{TSSP METHODOLOGY}

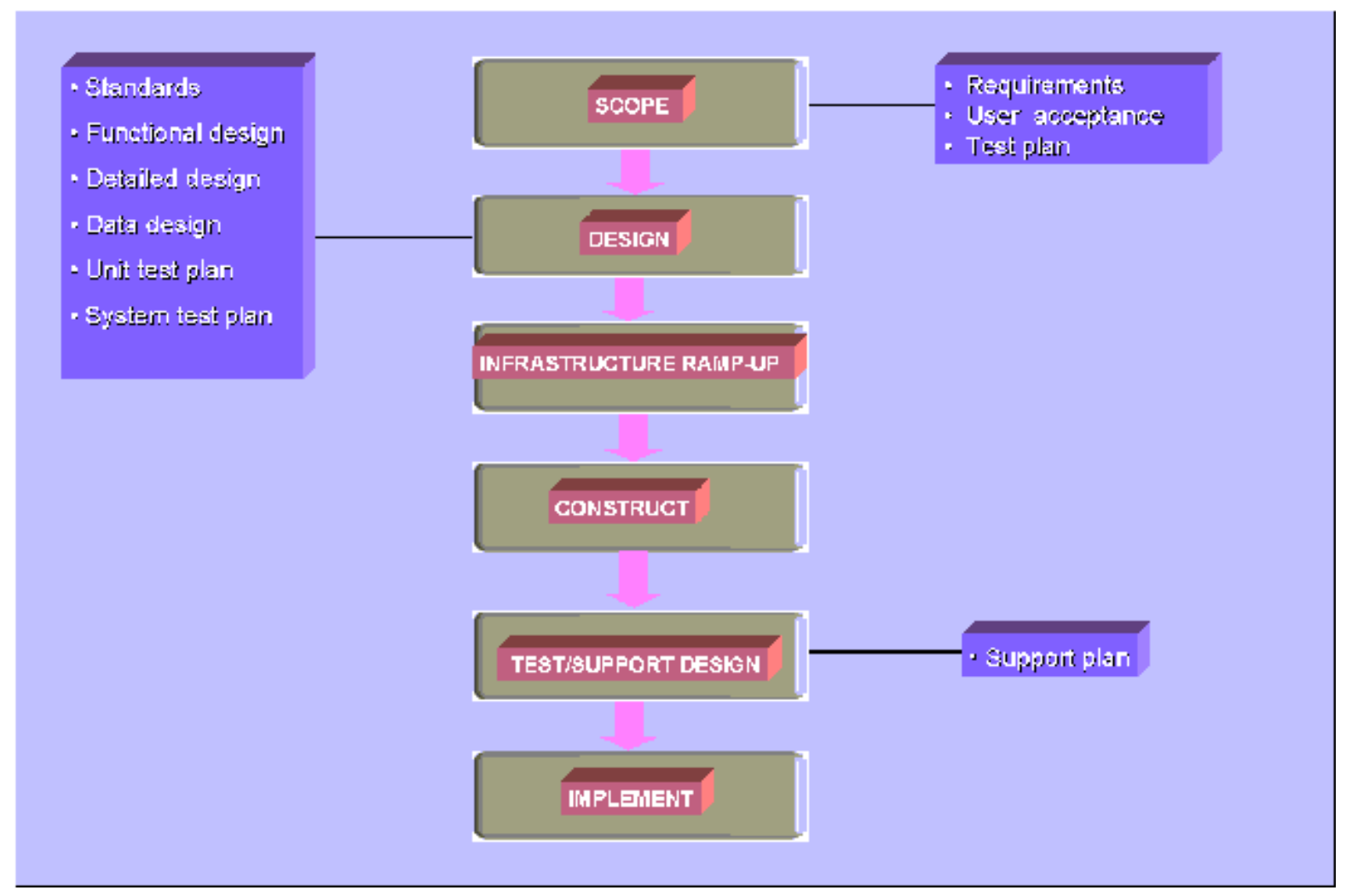

Hill (1998:203) states that technological problem solving is open-ended and creative. In creation and invention, there are always states of order and disorder (Hill, 1998:216). However, practice reveals that it is also a systematic, step-by-step guided process. Research and practice confirms that information system designers frequently lack a picture of the whole system. To accommodate students' needs for structured guidelines in information system design the following checklists and guidelines were planned for the technological stages:

- Web design checklist (WDC)

- Problem solving checklist (PSC)

- Decision-making checklist (DMC)

- Critical-thinking guidelines (CTG)

- Web design principles (WDP)

- Collaborative group guidelines (CGG)

Providing learners with explicit indicators of what is expected from them could increase selfmonitoring of their own design process and reflective thinking in general. Thus, we have a very structured information system learning environment. Students should also learn the structure of a field study (Bruner, 1966).

It was assumed that the technological stages would help learners in problem analysis through guided research of a case study, resource tasks and capability tasks. By planning to provide structured guidelines and an overview of the system development steps (including system analysis tools, programmeming tools and database tools) students will create a link between methodological steps in system design. This could contribute to self-reflection as learners mentally review the sequence, that is go over the steps. Structured tasks are supported by research (e.g. Van der Sanden, 1986; referred to by Doornekamp and Streumer, 1996: 65). 
It was assumed that Web design as a technological problem solving process could be better performed with the help of technological stages. Through technological stages learners could concentrate on research, market their ideas, and efficiently perform problem analysis using mind tools and structured guidelines. It could help learners to create an image of the whole system that is very often not seen in the information system design environment.

To conclude, learners need to develop an understanding of the required concepts and skills in using a range of mind tools, perception of the necessary steps, and procedures in information system design before they emerge into innovation. They have to be taught the technological stages that could help in problem analysis, extensive research and critical thinking.

\section{References}

Ankiewicz, P.J., De Swardt, A.E. and Stark, R. 2000. Technology education: principles, methods and techniques of Technology Education I, Johannesburg: RAU College for Education and Health.

Beyer, B.K. 1991. Teaching thinking skills: a handbook for secondary school teachers. Boston: Allyn and Bacon.

Bruner, J.S. 1966. Towards the theory of instruction. Cambridge Mass.: The Bellknap Press of Harward University Press.

Carver, S.M., Lehrer, R., Connell, T. and Erickson, J. 1992. Learning by hypermedia design: issues of assessment and implementation. Educational Psychologist, 27(3):385-404.

De Vries, M.J. 1999. Avoiding the pitfalls of a 'high tech hype': teaching and learning basic concepts of and in technology. Proceedings of RauTec Conference, 20.

Department of Education, 1997. Draft policy - senior phase. Policy document. Pretoria.

Doornekamp, B.G. and Streumer, J.N. 1998. Problem solving in teaching/learning packages for technology. International Journal of Technology and Design Education, 6:61-82.

Eggen, D. and Kauchak, D. 1996. Strategies for teachers: teaching content and thinking skills. Boston: Allyn and Bacon.

Fogarty, R. and McTighe, J. 1993. Educating teachers for higher order thinking: the three-story intellect. Theory into practice, 32(3):161-167.

Gardner, H. and Hatch, T. 1983. Multiple intelligences go to school: educational implications of the theory of multiple intelligence. Educational Researcher, 18(11):4-10.

Greenberg, J. and Lakeland, J.R. 1999. Building professional Web sites with the right tools. Upper Saddle River: Prentice Hall.

Gunter, M.A., Estes, T.H. and Schwab, J. 1995. Instruction: a models approach. 2nd ed. Boston: Allyn and Bacon.

Harel, I. and Papert, S. 1990. Software design as a learning environment. Interactive learning environments, 1(1):1-32.

Hennessy, S. and McCormick, R.1998. The general problem solving process in technology education. Learning Technology, 94-106.

Hill, A.M. 1998. Problem solving in real life contexts: an alternative for design in technology education. International Journal of Technology and Design Education, 8:203-220. 
Iowa Department of Education 1989. A guide to developing higher order thinking across the curriculum. Des Moines, IA: Department of Education. (ERIC Document Reproduction Service No. ED 306 550).

Johnsey, R. 1995. The design process - does it exist? A critical review of published models for the design process in England and Wales. International Journal of Technology and Design Education, 5:199-217.

Johnson, S.D. 1997. Learning technological concepts and developing intellectual skills. International Journal of Technology and Design Education, 7:161-180.

Jonassen, D.H. 1991. Representing the expert's knowledge in hypertext. Impact Assessment Bulletin, 9(1):93-105.

Jonassen, D.H. 1993. Changes in knowledge structures from building semantic net versus production rule representations of subject content. Journal of Computer-Based Instruction, 20(4):99-106.

Jonassen, D.H. 1996. Computers in the classroom: mindtools for critical thinking, New Jersey: Prentice-Hall.

Jones, A. 1997. Recent research in learning technological concepts and processes. International journal of technology and design education, 7:83-96.

Komers, P.AM., Jonassen, D.H., and Mayes, T.M. 1992 Cognitive tools for learning, Heidelberg: Germany: Springer-Verlag.

Laurillard, D. 1994. Rethinking university teaching. London: Routledge.

Lehrer, Erickson and Connell, 1996. Learning by designing hypermedia documents. Computers in Schools, 10.

Little, S.B. 1993 The technical communication internship and application of experiential learning theory. Journal of Business Technical Communication, 7(4):423-451.

Mayer, R.E. 1992. Thinking, problem solving, cognition. New York: W.E. Freeman.

McGrath, G., Cumaranatunge, C., Ji, M., Chen, H., Broce, W. and Wright, K. 1997. Multimedia science projects: Seven case studies. Journal of research on computing in education, 3(1):18-37.

McMurdo, G. 1998. Evaluating Web information and design. Journal of Information Science, 24 (3):192-204.

Mebl, M.C. 1997. SAQA bulletin, 2(2).

Morris, M.E.S. and Hinrichs, R.J. 1996. Web page design: a different multimedia. USA: Sunsoft Press.

Perkins, N., Goodrich, H., Tishman and Owen., J.M. 1994. Thinking connections - learning to think and thinking to learn. California: Menlo Park.

Ridley, P.N. and Ridley, J. 1996. A context for evaluating multimedia. Computers in Libraries, 3:34-40.

Schnider, R.W. 1987. Mind tools for the gifted. Gifted child today, 10(3):46-48.

Shield, G. 1996. Learning technology through a process approach: The implementation of curriculum innovation through the pragmatic interventions of the teacher. International Journal of 
Technology and Design Education.

Simmons, P.R.J. 1993. Constructive learning: The role of the learner. In T. Duffy.

Smallwood, J. 1995. Technology discussion in the classroom. In Edminson, G.A. (ed.), Delivery systems: instructional strategies for technology education, ITEA: Reston VA.

South Africa. 1997. South African Qualification Authority (SAQA) Bulletin. Pretoria.

Starfield, A.M., Smith, K.A. and Bleloch, A.L. 1990. How to model it: problem solving for the computer age. McGraw-Hill, USA: R.R. Donnelley and Sons.

Technology 2005, 1996. Curriculum framework for teacher education. Draft document.

Vockell, E. and Deusen, R.M. 1989. The computer and higher order thinking skills. Watsonville, CA: Mitchell Publishing Inc.

Von Wodtke, M. 1993. Mind over media - creative thinking skills for electronic media. New York: McGraw-Hill.

Welch, M. 1998. Students' use of three-dimensional modeling while designing and making a solution to a technological problem. International Journal of Technology and Design Education, 8:241-260.

Wheatley, G.H. 1991. Constructivist perspectives on science and mathematics learning, Science Education, 75(1):9-21.

\section{Disclaimer}

Articles published in SAJIM are the opinions of the authors and do not necessarily reflect the opinion of the Editor, Board, Publisher, Webmaster or the Rand Afrikaans University. The user hereby waives any claim he/she/they may have or acquire against the publisher, its suppliers, licensees and sub licensees and indemnifies all said persons from any claims, lawsuits, proceedings, costs, special, incidental, consequential or indirect damages, including damages for loss of profits, loss of business or downtime arising out of or relating to the user's use of the Website.

ISSN 1560-683X

Published by InterWord Communications for the Centre for Research in Web-based Applications, Rand Afrikaans University 